\title{
Abies sachalinensis var. sachalinensis oil
}

National Cancer Institute

\section{Source}

National Cancer Institute. Abies sachalinensis var. sachalinensis oil. NCI Thesaurus. Code C107255.

The essential oil of Abies sachalinensis var. sachalinensis. Sakhalin oil is said to promote relaxation. 